\section{Cerebral thrombosis in two patients with malabsorption syndrome treated with vitamin $K$}

Thrombosis may be a complication in inflammatory bowel disease. ${ }^{12}$ We report the occurrence of cerebral arterial thrombosis in two patients with malabsorption syndromes due to coeliac disease treated with vita$\min \mathrm{K}$.

\section{Case reports}

(1) A 59-year-old woman had for 20 years suffered from episodes of abdominal pains and diarrhoea and had been constantly underweight. She was admitted to hospital in 1977 because of increasing diarrhoea, progressive weight loss, and fluid retention. She weighed only $40 \mathrm{~kg}$ and had generalised oedema and subcutaneous ecchymosis. Her erythrocyte sedimentation rate (ESR) was $6 \mathrm{~mm}$ in $1 \mathrm{~h}$, haemoglobin concentration $12.6 \mathrm{~g} / \mathrm{dl}$, platelet count $370 \times 10^{\circ} / 1\left(370000 / \mathrm{mm}^{3}\right)$, and thrombotest (TT) $<5 \%$. Serum concentrations were: calcium $1.05 \mathrm{mmol} / 1(4.2 \mathrm{mg} / 100 \mathrm{ml})$, iron $8 \mu \mathrm{mol} / 1(44.6 \mu \mathrm{g} /$ $100 \mathrm{ml})$, total iron binding capacity $14 \mu \mathrm{mol} / 1(74 \mu \mathrm{g} / 100 \mathrm{ml})$, albumin 25 $\mathrm{g} / \mathrm{l}$, cholesterol $3.13 \mathrm{mmol} / \mathrm{l}(120.8 \mathrm{mg} / 100 \mathrm{ml})$. Jejunal biopsy showed partial villous atrophy and infiltration of chronic inflammatory cells. She was treated immediately with fluids, electrolytes, albumin, vitamin $\mathrm{K} 10 \mathrm{mg}$ intravenously, and a gluten-free diet. The subsequent TT values are shown in the figure. Twelve days later she developed left-sided hemiplegia. She died three months later. Necropsy showed slight atheroma, old ischaemic infarctions in the left hemisphere and pons, and a recent thrombus in the left hemisphere. Extensive histological examination of the small intestine confirmed the findings of earlier biopsies.

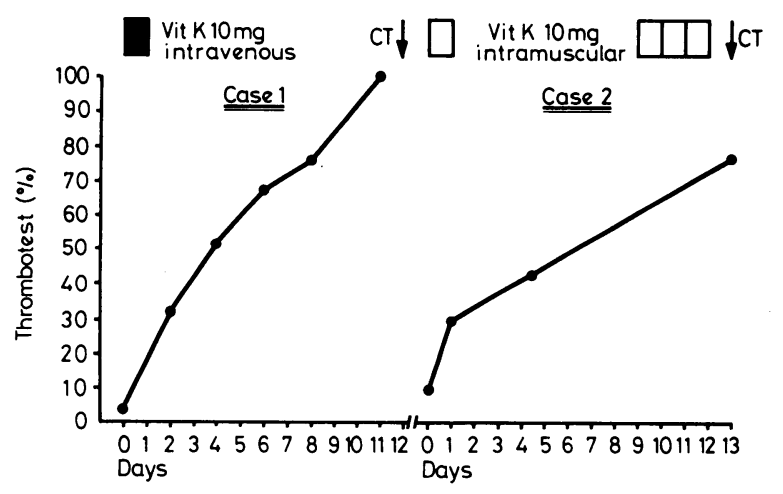

Trombotest (TT) values before and after vitamin $\mathrm{K}$ substitution in two patients with malabsorption syndromes. Onset of cerebral thrombosis (CT) indicated by arrow.

(2) A 60-year-old man had since childhood suffered from episodes of watery, non-bloody diarrhoea and was constantly underweight. In 1971 he had severe osteoporosis and steatorrhoea. In 1979 he was operated on for an ileocaecal volvulus. No resection was needed. After that his diarrhoea increased. On admission to hospital four months later he weighed $41 \mathrm{~kg}$ and had generalised oedema. His ESR was $12 \mathrm{~mm}$ in $1 \mathrm{~h}$, haemoglobin concentration $11.7 \mathrm{~g} / \mathrm{dl}$, platelet count $298 \times 10^{\circ} / 1\left(298000 / \mathrm{mm}^{3}\right)$, TT $10 \%$. Serum concentrations were: calcium $2.02 \mathrm{mmol} / 1(8.2 \mathrm{mg} / 100 \mathrm{ml})$, cholesterol 2.61 $\mathrm{mmol} / \mathrm{l}(100.7 \mathrm{mg} / 100 \mathrm{ml})$, and albumin $23.7 \mathrm{~g} / 1$. His faecal fat was $32 \mathrm{~g} / 24 \mathrm{~h}$. Biopsy of the small intestine showed partial villous atrophy with chronic inflammation. The patient was given a gluten-free diet, corticosteroids, and vitamin $\mathrm{K} 10 \mathrm{mg}$ intramuscularly. The subsequent $\mathrm{TT}$ values are shown in the figure. Twelve days after starting vitamin $K$ treatment the patient developed right-sided hemiplegia. Cerebral computed tomography showed a large ischaemic infarction in the left hemisphere.

\section{Comment}

Both these patients had chronic intestinal inflammation and malabsorption. Both had partial villous atrophy but neither responded clinically to a gluten-free diet. That is not unusual in older patients with a life-long history of idiopathic steatorrhoea. Thrombotic events have been described in chronic intestinal diseases, ${ }^{1-3}$ but the only case we know of with coeliac disease and thrombosis was in a 49-yearold patient who developed disseminated intravascular coagulation three months after starting on a gluten-free diet. ${ }^{2}$ Our patients had a major cerebral thrombosis during treatment for malabsorption. Both had a severe deficiency of the vitamin-K-dependent coagulation factors and responded to vitamin $K$ treatment with a return of the prothrombin time to normal. Their thrombotic episodes were directly associated with the resolution of the vitamin $\mathrm{K}$ deficiency. Perhaps, like patients with other intestinal inflammatory diseases, ${ }^{4} 6$ they had an increased tendency to thrombosis and this was prevented so long as their blood coagulation was deficient as a consequence of malabsorption.

These two cases suggest that great care should be taken not to treat a long-standing vitamin $\mathrm{K}$ deficiency in coeliac disease too abruptly. This may also apply to patients with other chronic intestinal diseases associated with a secondary malabsorption syndrome. If bleeding does occur treatment with plasma infusions or small doses of vitamin $\mathrm{K}$ would be preferable, guided by observation of the prothrombin time. Otherwise the vitamin $\mathrm{K}$ deficiency should not be specifically treated since it will gradually diminish as treatment with a gluten-free diet or corticosteroids, or both, takes effect.

${ }^{1}$ Borda IT, Southern RF, Brown WF. Cerebral venous thrombosis in ulcerative colitis. Gastroenterology 1973;64:116-9.

2 Ryan FP, Timperley WR, Preston FE, Holdsworth CD. Cerebral involvement with disseminated intravascular coagulation in intestinal disease. f Clin Path 1977;30:551-5.

3 Gvaef V, Baggenstoss AH, Sauer WG, Spittell JA. Venous thrombosis occurring in non-specific ulcerative colitis. A necropsy study. Arch Intern Med 1966;117:377-82.

- Lam A, Borda II, Inwood MJ, Thomson S. Coagulation studies in ulcerative colitis and Crohn's disease. Gastroenterology 1975;68:245-51.

' Lee JC, Spittell JA, Sauer WG, Owen CA, Thomson JH. Hypercoagulability associated with chronic ulcerative colitis: changes in blood coagulation factors. Gastroenterology 1968 ;54:76-9.

(Accepted 9 May 1980)

Department of Medicine, Regionsykehuset, University of Tromsø, 9012. Tromsg, Norway

JON FLORHOLMEN, MD, resident in medicine

HELGE WALDUM, MD, lecturer in medicine

ARNE NORDØY, MD, professor in medicine

\section{Dangers of storing glass syringes in surgical spirit}

Dangers associated with using surgical spirit instead of industrial methylated spirit for storing insulin syringes may not be well known. We report details of a patient in whom severe complications developed.

\section{Case report}

A 28-year-old woman was referred to the microbiology laboratory because of bilateral abscesses of the thigh. She had had moderately severe diabetes for 14 years and currently was using Actrapid MC 14 units and Monotard MC 32 units daily. For the past two years she had been storing her insulin syringe (Everett) in surgical spirit prescribed by the diabetic outpatient department and her general practitioner. Previously she had always used industrial methylated spirit. After using surgical spirit for about six months she noticed that she had developed several swellings of varying sizes in the deep tissues of her thighs at injection sites. The swellings were only slightly painful but some were becoming superficial and she had received medical advice that this was an uncommon but unfortunate complication of multiple injections. She was referred to the accident department at Wycombe Hospital in July 1979 with large bilateral painful swellings in both thighs, which appeared to be multiloculated abscesses. As these were thought to be infected they were incised and a sample of the pus was sent for culture; ampicillin and flucloxacillin were prescribed. Culture was sterile, however, and healing was slow with poor granulation and excessive scar tissue. Staphylococci were presumed to be the likely infecting organism, so the patient, her husband and their son were screened for nasal carriage : findings were negative. Our patient attended the laboratory at intervals over the next few months with further 
smaller swellings, which caused little pain and discharged purulent fluid no further antibiotic treatment was given and all cultures were sterile. In December 1979 she ran out of surgical spirit and had to sterilise her syringe with boiling water. While reading the syringe instructions she noted that the manufacturers specifically advised the use of industrial methylated spirit for storage. She therefore changed her storage method and has had no further trouble at her current insulin injection sites on the abdomen. The swellings in her thighs, however, have continued to develop and discharge and she has many scars that are cosmetically disfiguring.

\section{Comment}

It may not be widely known that surgical spirit contains additives such as castor oil, methyl salicylate, and diethylphthalate as well as industrial methylated spirit. Constant use results in a build-up of oily residues on the inner surface of the syringe, and on occasions free passage of the barrel may become obstructed. On the other hand, industrial methylated spirit consists wholly of volatile alcohols and leaves no residue, the British Pharmacopoeia specification being no more than $0 \cdot 1 \% \mathrm{v} / \mathrm{v}$ compared with approximately $5 \% \mathrm{v} / \mathrm{v}$ for surgical spirit. There is little doubt that these oily residues would be sufficiently miscible with certain types of insulin to be deposited with the latter at the injection site. This patient had also noted that the use of antiinflammatory creams, which contain methyl salicylate, caused an extensive erythema and irritation of her skin.

It appears that surgical spirit, despite its clinical connotation, may be a dangerous storage fluid and it is undoubtedly less free of additives than industrial methylated spirit, even though the term "industrial" implies a greater degree of impurity. Doctors working in diabetic outpatient departments or general practice may therefore be tempted to insist on surgical spirit being used. The incidence of necrosis at injection sites is not known and it must be rare without an associated hypersensitivity to the additives in surgical spirit. Nevertheless, it is wise and imperative that the manufacturers' instructions, which emphasise the use of industrial methylated spirit and give details of the method of dispersing the volatile alcohols, are carefully followed.

Recent examination of this patient, who has been using industrial methylated spirit for three months, shows no sign of swellings in the current injection sites. Although we have not carried out tests for hypersensitivity the surgical spirit probably caused the complications.

(Accepted 9 May 1980)

Department of Microbiology, Wycombe General Hospital, High Wycombe, Bucks HP11 2TT

D A LEIGH, MB, BS, consultant microbiologist

Hinders Leslies Limited, London E17 6EJ

G W HOUGH, BSC, technical manager

\section{A better system for polio vaccination in developing countries?}

Poliomyelitis is an important health problem in developing countries, and unfortunately there are serious difficulties in preventing it by the use of oral polio vaccine. The vaccine. is manufactured in only a few developing countries; elsewhere it has to be transported long distances and yet must be kept constantly cold to maintain its potency. Even when fully potent vaccine is given three doses are insufficient for effective immunisation in countries like India because of low seroconversion rates. ${ }^{2}$ Several methods have been suggested to improve the efficacy of oral polio vaccine: increasing the potency; giving monovalent rather than trivalent vaccine; and giving five rather than three doses. ${ }^{1-3}$ But all these methods add to the problems of immunisation, and we have therefore designed and tested a strategy of giving the vaccine that is simpler and yet improves its efficacy.

\section{Subjects, methods, and results}

All children aged from 3 months to 5 years in one village $10 \mathrm{~km}$ from Vellore were given their first dose of oral polio vaccine during one morning in August 1978. Second and third doses were given at monthly intervals, again during one morning, in September and October. We collected blood from the children immediately before the first dose and four weeks after the third dose and tested all the sera for the presence and titres of neutralising antibody, at a starting dilution of $1 / 8$, against 100 TCID $_{50}$ of poliovirus $\underline{\square}$ types 1,2 , and 3 .

Two batches of imported oral polio vaccine were purchased from the supplier and brought to the laboratory in insulated containers containing ice. $Q$ They were stored at $-20^{\circ} \mathrm{C}$ and tested for potency just before use by titration $\subseteq$ in primary bonnet-monkey kidney cells. The vaccine was taken to the village in insulated cold boxes. Its potency was poor-in the first batch $10^{4} \mathrm{TCID}_{50} \mathrm{\omega}$ per dose and in the second $10^{4.5} \mathrm{TCID}_{50}$ (the recommended potency is $\overrightarrow{0}$ $10^{6.1} \mathrm{TCID}_{50}$ ). The first batch was given for the first dose and the second for subsequent doses.

Eighty children were vaccinated, but paired sera were available from only $\frac{\bar{S}}{\bar{S}}$ 51. Among them 34,26, and 21 were without antibody before vaccination to $\mathbb{D}$ types 1,2 , and 3 poliovirus respectively, and 25,25 , and 15 responded with antibody production (table).

Seroresponse after cluster vaccination with substandard oral polio vaccine $(O P V)$ compared with seroresponse after sporadic vaccination with potent OPV.

\begin{tabular}{lcccc}
\hline & \multicolumn{3}{c}{ Seroconversion rate $(\%)$} & Reference \\
\cline { 2 - 4 } Vaccine and strategy & Type 1 & Type 2 & Type 3 & No \\
\hline $\begin{array}{c}\text { Poor vaccine and } \\
\text { cluster strategy }\end{array}$ & 74 & 96 & 71 & $\begin{array}{c}\text { Present } \\
\text { study }\end{array}$ \\
$\begin{array}{c}\text { Potent vaccine and } \\
\text { sporadic strategy }\end{array}$ & 69 & 90 & 76 & 1 \\
\hline
\end{tabular}

\section{Comment}

In a previous study when we gave three doses of fully potent oral $N$ polio vaccine to children in an immunisation clinic we obtained seroconversion rates of $69 \%, 90 \%$, and $76 \%$ to the three serotypes (table). The immunisations were spread over several weeks and the children $\bar{\omega}$ were not from any one community. The seroconversion rates obtained in the present study were equally good even though the vaccine had a $\vec{\oplus}$ potency only $0 \cdot 7-2 \cdot 1 \%$ of that recommended. We assume that the rates would have been considerably better if we had used fully potent vaccine.

The comparatively good seroconversion rates were unlikely to be due to wild poliovirus infection in the community since response was seen against all three serotypes in a short time, whereas natural infec- 응 tion occurs with one type at a time. ${ }^{4}$ We believe that the most probable $\varrho$ reason was that the vaccine viruses became the enteric viral flora among $\overrightarrow{\vec{B}}$ the children for a time and thus enhanced the overall infection rates. 3 The spread of vaccine virus infection has been recognised by several investigators. The phenomenon was shown strikingly in a study in orphanages in Bandung-where 40 young inmates were given two doses of oral polio vaccine six weeks apart and 99 older inmates were given placebo, and yet seroconversion rates were roughly equal in both groups. ${ }^{5}$ This effect is likely to be greatest when large groups are $\bar{\sigma}$ vaccinated in a short time ("cluster" or "pulse" immunisation) and minimal with sporadic vaccination.

We think that if these results are confirmed when fully potent oral $\frac{0}{3}$ polio vaccine is used this cluster technique may be a considerable improvement on existing strategies of immunisation.

This study was supported in part by the Indian Council of Medical $N$ Research.

1 John TJ. Antibody response of infants in tropics to five doses of oral polio $\mathrm{N}$ vaccine. $B r$ Med $\mathcal{f} 1976 ; 1: 812$.

2 Domok I, Balayan MS, Fayinka OA, Skrtic N, Soneji AD, Harland PSEG. Factors affecting the efficacy of live poliovirus vaccine in warm climates. Bull WHO 1974;51:333-47.

3 John TJ, Devarajan LV, Balasubramaniam A. Immunisation in India with trivalent and monovalent oral poliovirus vaccines of enhanced potency. Bull WHO 1976;54:115-7.

4 John TJ, Kamath KR, Feldman RA, Christopher S. Infection and disease in a group of south Indian families. 9. Poliovirus infection among pre- $O$ school children. Indian $\mathcal{F}$ Med Res 1970;58:551-5.

5 Suwaryo SI, Permadhi H, Alisjahbana A, Thaila S. Trial of oral polio- $\frac{\rho}{\mathbb{D}}$ vaccination on children of several orphanages and nurse families in $\varrho$ Bandung. Paediatrica Indonesiana 1976;16:255-68.

(Accepted 9 May 1980)

Christian Medical College and Hospital, Vellore 632004, Tamil $\frac{\varrho}{7}$ Nadu, India

T JACOB JOHN, FRCPE, PHD, professor and head of department of virology ABRAHAM JOSEPH, MD, DCH, reader in department of community health $P$ VIJAYARATHNAM, senior technician in department of virology 